\title{
EL ESCRITOR NO ES NADA, NADIE: \\ Saer contra una estética latinoamericana
}

Rafael Arce*

Universidad Nacional del Litoral-CONICET

1.

En un ensayo estupendo, Alejo Carpentier señala la dificultad que entraña dar definiciones sobre nociones harto complejas que atraviesan la historia del arte y de la literatura. No obstante, su recorrido lo obliga a asumir cierta definición o, mejor, cierto rasgo conceptual que permitiría el acceso a una cierta definición, para el caso de su interés, del barroco, noción harto compleja que lo ayudará para llegar a la de lo real maravilloso. Después de una breve síntesis acerca de los avatares de esta noción a través de la historia del arte, ilustrada sobre todo por ejemplos tomados de la arquitectura, Carpentier se decide por este rasgo capital: lo que caracterizaría más propiamente al barroco como posición estética es un declarado horror al vacío. La caracterización, el rasgo conceptual, es de tipo causal: el horror al vacío sería la causa, el motivo, del movimiento, o de la actitud más bien, barroca.

La caracterización, poética si se quiere, porque viene de un escritor y en una modulación de tipo ensayística, no carece de rigor. Es, por lo tanto, teóricamente sólida y retóricamente estimulante.

También los colastiné, la tribu americana que protagoniza El entenado, la novela de Saer sobre el descubrimiento de América publicada en 1983, sufre en carne propia el horror al vacío. Este horror es la causa de su periódica orgía, que comienza con una cacería humana y finaliza con la devolución del sobreviviente testigo a su hogar primigenio, luego del canibalismo, la borrachera, el incesto y la

\footnotetext{
" Rafael Arce es Profesor y Licenciado en Letras por la Universidad Nacional del Litoral. Es becario del CONICET y realiza actualmente su doctorado en la Universidad Nacional de Rosario con un plan de tesis sobre el conjunto de la obra de Saer. Ha publicado numerosos artículos sobre el tema en revistas de Argentina y del extranjero.
} 
muerte. Si se tiene en cuenta que El entenado aparece como uno de los pocos momentos de la obra saeriana donde el tópico de lo americano tiene un lugar central, uno podría pensar muy bien que esta novela, entre otras cosas, es un carpetazo fundamental a la posición estética de lo real maravilloso. La orgía colastiné ha sido ampliamente leída en clave freudiana, levi-straussiana, historiográfica, política, etc., y es verdad que el sofisticado andamiaje de la novela habilita estas lecturas. Pero me pregunto si esta orgía, a la luz del pensamiento carpentieriano, no es más pedestremente (más literalmente) el barroco americano, propio de lo real maravilloso, que la tribu pone en juego, cíclicamente, para tapar, con su desmesura, el vacío. Vacío que es, justamente, la metafísica misma del hombre saeriano, y que opone, como imaginario geográfico, a la desmesura de la selva americana, el despojamiento radical de la llanura pampeana.

Comienzo, en cierto modo, por el final. Después del 83, pocas veces se ocupa Saer de la cuestión de la literatura latinoamericana, salvo para encarnizarse alguna que otra vez con García Márquez y afirmar en alguna entrevista que él es argentino, no latinoamericano. ${ }^{1}$ Es precisamente El entenado la obra con la que, según muchos críticos, y en un esquema que ya es vulgata entre los saerianos, comienza la obra madura de Saer, su tercera etapa, la definitiva. $^{2}$ La polémica que Saer establece con una idea de literatura latinoamericana data de los comienzos mismos de su obra. Un esquema historizador no es vano aquí. En su primera obra, En la zona (1960), Saer nos presenta un volumen de cuentos de herencia borgiana y chandleriana, y, en un prólogo también borgiano, caracteriza brevemente al hombre argentino: "Los

\footnotetext{
${ }^{1}$ Ver Diálogo Piglia-Saer. Por un relato futuro, Centro de Publicaciones de la Universidad Nacional del Litoral, Santa Fe, 1990 y Saer, Juan José, "Soy argentino, no latinoamericano", entrevista con Leonardo Moledo, "Cultura y Nación”, Clarín, Buenos Aires, 15 de enero de 1987.

${ }^{2}$ Ver especialmente Stern, Mirta (1984), "Juan José Saer: construcción y teoría de la ficción narrativa", en Hispamérica, Año XIII, Nº 37, 15-30; Gramuglio, María Teresa, (1986), "El lugar de Saer", en (1986) Juan José Saer por Juan José Saer, Ed. Celtia, Buenos Aires, 262-263; Dalmaroni, Miguel y Merbilháa, Margarita (2000), “'Un azar convertido en don'. Juan José Saer y el relato de la percepción", en Noé Jitrik: Historia crítica de la literatura argentina, Tomo 11 (dirigido por Elsa Drucaroff) "La narración gana la partida", Buenos Aires, Emecé, 321-343; Premat, Julio (2002), La dicha de Saturno, Beatriz Viterbo Editora, Rosario, 2002:33-34.
} 
argentinos somos realistas, incrédulos. A caballo sobre nuestra indefinición y sobre nuestra condición posible, aspirar a la inmortalidad y a la grandeza clásica serían modos triviales de un romanticismo que no nos cuadra." (Saer, 1960:421).

La palabra realista no parece tener aquí una connotación literaria, pero es inevitable que ese sentido se deslice, subrepticio, y deje ya una marca en el origen mismo de la obra, como una rúbrica.

En lo que la crítica llama su primera etapa, de aprendizaje o inmadura, y que llega, o bien hasta Unidad de lugar (1967) o bien, más marcadamente, hasta Cicatrices (1969), su primera novela de madurez, abundan las obras que en aquella época algunos críticos de poco criterio confundieron con regionalismo, realismo ingenuo o naturalismo anacrónico. ${ }^{3}$ En Cicatrices, el segundo narrador y protagonista, Sergio Escalante, escribe una serie de ensayos de tono paródico o burlón, con títulos inverosímiles. Piensa titular al conjunto Momentos fundamentales del realismo moderno. Uno de ellos se titula El realismo mágico de Lee Falk y de él afirma que encuentra en el universo del historietista las pautas estéticas de la novela latinoamericana moderna. Este chiste salvaje, corrosivo, enuncia sin embargo una clara posición, si pensamos que dos años antes la publicación de Cien años de soledad venía a coronar un espectro estético que, más allá de sus obvias diferencias, habían contribuido a afianzar en América, desde veinte años atrás, obras como la de Asturias o la de Carpentier.

Cinco años más tarde Saer publica su cuarta novela, quizás su obra más ambiciosa y radical. César Aira afirma de ella que es "un experimento con el tiempo, insólitamente borgiano" (Aira, 1987:67). Es también un homenaje, conjunto y rigurosamente elaborado, tanto al Ulises como a La Odisea. En esta novela monstruosa, escrita en una prosa impecable, cuidadosa hasta la manía, el paisaje es la isla salvaje y desnuda, y los protagonistas son tristes y pobres pescadores y pueblerinos. $Y$ por si fuera poco, y de modo suplementario, en el mismo momento en que el fantástico de Borges y el realismo mágico de García

\footnotetext{
${ }^{3}$ Para un panorama general de la historia de estas lecturas, ver Dalmaroni, Miguel, "El largo camino del 'silencio' al 'consenso'. La recepción de Saer en la Argentina”, en El entenado, Saer, Juan José -Glosa, Paris, Col. Archivos- ALLCA XX, edición crítica a cargo de Julio Premat, 607664, (en prensa).
} 
Márquez fascinaban a Europa y al mundo, Saer no tiene mejor idea que titular a su magistral novela El limonero real.

A este esquema breve hay que sumar de modo paralelo los ensayos que Saer fue escribiendo desde finales de los 60 y que recién salen a la luz como libro en 1989, en 1993 y en 1999. Varios de los más importantes ensayos se ocupan, de modo directo u oblicuo, del problema de la literatura latinoamericana. De modo esquemático, podríamos decir que la actitud saeriana respecto de una literatura latinoamericana es de rechazo total. Ahora bien, ¿en qué consiste este rechazo?

Antes que nada, es necesario sortear un problema complejo y es la heterogeneidad misma del enemigo estético de Saer. Se superponen y confunden nociones como "literatura americana", "barroco americano", "realismo mágico", "real maravilloso", "boom" y se entreveran escritores tan dispares como Asturias, Cortázar y Lezama Lima. La bibliografía crítica sobre el tema no hace más que aumentar la confusión. ${ }^{4}$ Podríamos decir que la bibliografía es de por sí barroca. Bastará, de modo preliminar, con circunscribir el problema, de modo de hacerlo más fácilmente manejable, aunque la simplificación borre, en principio, los matices. En cierto sentido, la posición saeriana lo habilita: para Saer, los matices, o incluso las visibles diferencias, no tienen ninguna importancia, puesto que su posicionamiento estético tiende a igualar esas distinciones y, lo que es más importante (lo veremos al final), cuando uno va al fondo de la cuestión descubre que esa igualación es, desde cierto punto de vista, legítima. Además, yendo a las fuentes, uno puede encontrar, a modo de síntesis, el oponente perfecto, tanto por la consistencia de su posición teórica, como por la trabazón meticulosa entre obra novelesca y ensayística. Este oponente que oficiará de contrapunto (ya lo anticipé) es Alejo Carpentier.

\section{2.}

Se podría decir que, a primera vista, el cosmopolitismo saeriano, de raíz borgiana, se opone al americanismo carpentieriano. Pero esto es una

\footnotetext{
${ }^{4}$ Para un excelente balance bibliográfico sobre el tema, ver Llanera, Alicia (1997), Realismo mágico y lo real maravilloso, una cuestión de verosimilitud, Hyspamérica, Madrid.
} 
simplificación que se presta a equívocos, porque el cosmopolitismo de Saer no es un posicionamiento previo sino el resultado de una cierta concepción de la tarea narrativa (y no es, al final, lo veremos, un cosmopolitismo, sino más bien su reverso), mientras que para Carpentier la literatura latinoamericana también aspira, como tal, a lo universal. Habrá que ser, entonces, más sutiles.

Vuelvo sobre el primer libro de Saer, titulado significativamente En la zona. Título que ha sido interpretado de modo diverso y que yo quisiera leer aquí en relación con el posicionamiento planteado. En el más célebre de sus cuentos, el último de la serie, "Algo se aproxima", cuento donde los críticos vieron, en germen y proyectado, el programa narrativo saeriano, dice un personaje:

En cierta medida, el mundo es el desarrollo de una conciencia. La ciudad que uno conoce, donde uno se ha criado, las personas que uno trata todos los días son la regresión a la objetividad y a la existencia concreta de las pretensiones de esa conciencia. Por eso me gusta América: una ciudad en medio del desierto es mucho más real que una sólida tradición. Es una especie de tradición en el espacio. (...) Yo escribiría la historia de una ciudad. No de un país, ni de una provincia: de una región a lo sumo. (Saer, 1960:517)

Lo más evidente de la cita es la concreción del proyecto enunciado: la saga saeriana es entre otras cosas la historia de la Zona, desde sus comienzos históricos hasta la actualidad, cruzando, quebrando, el esquema historicista con el tiempo mítico, con el mito arcaico del origen de la cultura en El entenado o la cosmogonía de El limonero real. La ciudad se opone, en la saga, al continente como objeto de narración.

Ahora bien, la ciudad tiene para este personaje un estatuto, digamos, fenomenológico: es aquello que la consciencia narradora puede aprehender. La consciencia es el atributo del narrador de la novela moderna, la consciencia en tanto consciencia narradora. La ciudad, la zona en tanto zona de percepción, es su espacio: esto es común a Joyce y a Robbe-Grillet, para citar dos obras de la tradición saeriana. Es a partir de esta posición fenomenológica (tomo acá la palabra en su sentido de vulgata filosófica, como se hace siempre en crítica literaria) que se despliega espacialmente América, esto es, el desierto. El desierto es también la falta de tradición o, dicho de otro modo, el posicionamiento irreverente del narrador americano en la gran tradición de occidente tal cual lo 
enuncia Borges en su celebérrimo ensayo. El desierto es además el imaginario de la literatura argentina, que comienza con Sarmiento y con Hernández: la llanura, la pampa.

Por el contrario, las prerrogativas estéticas de Carpentier deben necesariamente partir de América como totalidad: de ahí sus esfuerzos por unir, mediante ciertos lazos, la literatura de todo el continente, desde Argentina hasta México. Este posicionamiento es necesariamente esencialista: existe, previamente (y este previamente, lo veremos después, es fundamental), un "espíritu", una "sensibilidad", una "identidad", incluso un "documento humano", latinoamericanos. La novela americana tiene un compromiso con la esencia latinoamericana, una esencia humana y geográfica: lo propio de América Latina debe poder ser narrado o, mejor, "expresado", "traducido", por el escritor. De ahí que, para Carpentier, el novelista latinoamericano tenga como misión testimoniar a América Latina. ${ }^{5}$

A contramano, afirma Saer en su ensayo "La selva espesa de lo real": "Todo apriorismo ideológico del tipo: "Dado que soy latinoamericano, y que los latinoamericanos somos así, mi trabajo consistirá en describirnos tal cómo somos", implica una actitud tautológica, porque si de antemano se sabe lo que son los latinoamericanos, describirlos es inútil y redundante." (Saer, 1979: 271).

El narrador saeriano parte, por el contrario, de la nada más absoluta, del vacío, lo cual también tiene ecos fenomenológicos, porque recuerda la reducción trascendental: se suspende, primero, el juicio respecto de la existencia o no del mundo, para dejar que la cosa aparezca en cuanto fenómeno. Este es el desierto saeriano a partir del cual la realidad se presenta, sin que el narrador pueda postularla de antemano.

De lo que se trata es, en definitiva, del estatuto del narrador. Para Carpentier, el narrador, antes que la narración propiamente dicha, es, a priori, americano y esto lo determina de antemano o, mejor, determina el sentido de la tarea narrativa. Para Saer, ser narrador consiste, ante todo, en liberarse, antes de narrar, de cualquier atribución, incluso estética, porque bien claro deja Saer a cada momento que el narrador posee sólo una estética negativa: sabe mejor lo

\footnotetext{
${ }^{5}$ Carpentier, Alejo (1975), "Un camino de medio siglo", en ob. cit.
} 
que no debe hacer que lo que debe hacer. El narrador no es nada, nadie. Es, como el título de la novela de Musil, "el hombre sin atributos".

Es esta posición la que da como resultado, no un cosmopolitismo, sino su reverso. Es necesario entender que la anterioridad de la posición, digamos, estética, fundamenta este rechazo de un a priori identitario en relación con lo espacial y, en consecuencia, con lo nacional o lo continental, podríamos decir (más acorde con la moda de los estudios literarios): el rechazo de todo apriorismo respecto a una "identidad cultural”. Cuando Pichón Garay, en La pesquisa, vuelve a su ciudad después de más de una década de vivir en Europa, se extraña por la comprobación de que, ante el regreso, no se apodera de él ningún sentimiento ni emoción. Por fin, en un paseo en lancha, de vuelta a la ciudad, entre las islas, Pichón accede a la causa de esa falta de sentimientos:

...porque ahora es al fin adulto, y ser adulto significa justamente haber llegado a entender que no es en la tierra natal donde se ha nacido, sino en un lugar más grande, más neutro, ni amigo ni enemigo, desconocido, al que nadie podría llamar suyo y que no estimula el afecto sino la extrañeza (...), y que ese conjunto que incluye hasta los bordes mismos de lo inconcebible, no es en realidad su patria sino su prisión... (Saer, 1994:84-85)

Si el individuo cosmopolita se opone al individuo nacional o continental, al individuo identificado con un lugar, un pueblo o una cultura, el individuo saeriano aparece con un estatuto indecidible respecto de estas dos posiciones. Tanto al cosmopolita como al "culturalista" (digamos) le cabe la idea de familiaridad, de patria y de pertenencia, sea a un solo lugar, sea a la casa del mundo. Para el hombre saeriano, en cambio, la frontera entre lugar y mundo se borronea cuando ambas entidades son igualadas no por la familiaridad, sino por la extrañeza, por la no pertenencia: eso que podríamos llamar, con ecos blanchotianos, la experiencia de lo Exterior, la experiencia del Afuera.

3.

Esta diferencia capital entre las dos posiciones narrativas tiene innumerables consecuencias a varios niveles de las posiciones estéticas. El 
compromiso previo de Carpentier con un espacio y con una cultura determinados es también el compromiso con un cierto momento de la historia. Entiendo que para Carpentier, dados el estado de desarrollo tanto de la novela como de las sociedades de América Latina, el narrador ocupa un lugar similar al que Balzac le daba en el siglo XIX.

Cito a Carpentier: "Por lo tanto, no veo más camino para el novelista nuestro en este umbral del siglo XXI que aceptar la muy honrosa condición de cronista mayor, Cronista de Indias, de nuestro mundo sometido a trascendentales mutaciones, cuyos signos anunciadores aparecen ya en muchos lugares del mapa." (Carpentier, 1979:25).

El novelista americano es un cronista, como el narrador balzaciano: representa, debe representar, una época. Esto está, por supuesto, en las antípodas de la posición saeriana. Una vez más, para Saer, la anterioridad de lo estético (que no debe ser confundido con esteticismo) lo enfrenta a este punto de vista. En primer lugar, si el narrador no es nada ni nadie, no puede comprometerse con ninguna época, ni con la suya ni con ninguna otra. En segundo lugar, la relación estrecha entre narración e historicidad es, para Saer, un momento en la evolución de la forma narrativa, que coincide con la novela burguesa. De hecho, Saer llega a definir al realismo decimonónico como "adecuación de la escritura a una visión del hombre que se agota en la historicidad" (Saer, 1979:267). La novela del siglo XX, tal cual la entiende Saer, es aquella que rompe con la historicidad: el simbolismo en Joyce, la parábola en Kafka, las búsquedas míticas en Mann o en Pavese, sin abandonar, no obstante, un cierto "realismo", suponiendo que esta palabra tenga algún sentido todavía. Se podría decir: sin abandonar, a pesar de todo, la Historia.

Por supuesto, no estoy diciendo que la posición de Carpentier lo lleve a escribir en el siglo XX como Balzac. Pero Carpentier sigue sosteniendo para el siglo XXI la posición del narrador como cronista de la historia, que para Saer termina, de un modo definitivo, con Balzac. Por supuesto, esto es consistente con su punto de vista respecto de la anterioridad del narrador americano y de América como objeto de narración. Aunque Carpentier no lo dice, uno podría incluso agregar a favor de su tesis la discontinuidad histórica de América respecto de Europa, por lo que las tesis lukacsianas, que Saer sostiene con fervor y 
flexibilidad, podrían ser inaplicables a la novela de América Latina. Pero esto nos llevaría a una discusión interminable. Sintetizando, lo que para Saer está agotado es la anterioridad de la historia respecto de la narración. Nuevamente, esto no debe ser confundido con esteticismo, aunque sea traducible en esos términos, en el sentido en que para Saer se trata antes que nada de la forma novelesca tal y como se presenta en el siglo XX, lo cual tampoco negaría Carpentier, gran lector de la novela de todo Occidente. El problema es que la cuestión de la forma implica necesariamente la ruptura con la historicidad. Porque lo que para Saer constituyen las búsquedas narrativas propias de la novela moderna tienen como resultado (a comienzos del siglo $\mathrm{XX}$ ) una transformación radical de la concepción misma de la temporalidad. Esto es lo que la novela moderna le sabe a la historia y ahí están los trabajos de Paul Ricoeur y de Hayden White para demostrarlo. La fenomenología y la hermenéutica llevan la delantera a la historiografía en relación con la cuestión de la temporalidad y la novela de la primera mitad del siglo XX (Joyce, Virginia Woolf, Thomas Mann, Faulkner: la tradición de Saer) parece dialogar más con la filosofía que con la historia. La narración moderna interroga el tiempo, diría Saer; la historia, en cambio, lo presupone. Es esto lo que pareciera no comprender Carpentier.

Espacio, tiempo: categorías de la narración, previas, dadas, en una estética de lo real maravilloso; posteriores en la estética saeriana, sometidas a interrogación en la tarea narrativa misma. Esto no impide, en Carpentier, la discontinuidad temporal, sobre todo a través de modernas técnicas narrativas. Pero él mismo sostiene lo inconmovible de lo histórico detrás de la discontinuidad narrativa, por ejemplo para su El reino de este mundo. En Saer, su posición antihistoricista no le impide incorporar a sus narraciones elementos de la historia (el postperonismo, la dictadura, el descubrimiento de América, la inmigración en Argentina), pero estos no quedan nunca inconmovibles sino que son transformados por el trabajo narrativo. Uno puede hacer lecturas en clave política, como leer en la decadencia del personaje de Alfredo Barrios, en Responso (1964), el derrumbamiento de una época y de un proyecto de nación (el peronista). El problema es que jamás estas claves agotan, saturan, los problemas que la narración saeriana plantea. En el caso de Responso, el eco del realismo arltiano en trama y personaje hacen presentir al lector que el derrumbe de Barrios 
es más bien voluntario, querido, gozado: lo cual entra en tensión con la alegoría del postperonismo. Del mismo modo, y para seguir con la tradición novelesca de Saer, La montaña mágica convierte, en su desenlace, al sanatorio de tuberculosos en Europa toda, cuya enfermedad engendra la Primera Guerra Mundial. Pero es imposible agotar el sentido de la novela en esta fácil alegoría, del mismo modo que la omnipresencia del affaire Dreyfus en El busca del tiempo perdido permite, sí, anclar la summa proustiana a una época: pero que nadie confunda a Proust con un cronista de la decadencia de un modo de vida europeo, porque la búsqueda de la novela, la novela como búsqueda de sí misma, el narrador como antihéroe de una novela cuya imposibilidad se novela, deja en segundo plano, como telón de fondo, la Historia en sentido fuerte.

Lo cual me lleva, dicho sea de paso, al siguiente punto: la relación entre literatura y política. Al llegar a este punto, que se deriva de las dos posiciones tomadas, la separación es tajante: el sartrismo de Carpentier se opone al adornismo de Saer. Para Carpentier, el novelista tiene una función social que, en última instancia, da a su tarea artística la dimensión de un compromiso; en su caso, un compromiso con la revolución cubana y con el pensamiento de izquierda en América Latina. Saer, que jamás podría ser considerado alguien de derecha, sostiene, aún para la literatura latinoamericana, la autonomía del arte, autonomía que él entiende como libertad del artista, libertad que debe ser absoluta, como el vacío del que parte la narración: el único compromiso que existe es con la tarea narrativa misma y ese compromiso, al partir del vacío, ni siquiera es él mismo seguro. En la que podríamos llamar la novela de la dictadura de Saer (Nadie nada nunca, de 1980), el comienzo de la narración, que después se convertirá en estribillo, reza, evocando al Génesis: "No hay, al principio, nada. Nada." (Saer, 1980:11, 17, 59, 91, 136, 181, 211, 222). Esta anterioridad de la nada puede ser temporal, pero es por sobre todas las cosas una anterioridad de fundamento: impide una totalización de la alegoría política que se apodera de la novela marcando, reiterativamente, que lo político no es de ningún modo el fundamento ni el principio del ser humano sino, más bien, algo muy posterior a ese vacío ontológico del que también arranca la sociedad y la cultura según El entenado. 


\section{4.}

Ahora bien, llegado este punto, que es quizás el más superficial, el más evidente, me pregunto si no hay, en el fundamento de cada posición estética, algo todavía más anterior. ¿Qué significan, si retomamos el punto más problemático de la polémica, aquellas dos posiciones del narrador, esencialista una, vacía la otra? O, mejor, para interrogar de otro modo la posición antagónica: ¿qué significa ser un narrador americano?

A pesar de la consistencia y la elegante argumentación de Carpentier, hay ciertos puntos de vista que, si bien no hacen mella en la coherencia de su posición, por lo menos obligan a interrogarse una vez más sobre su estatuto. Dicho de otro modo: ¿es la posición de lo real-maravilloso, derivada de la definición del barroco, una posición original o más bien aparece, en su fundamento último, como derivada?

La sospecha recae sobre cuestiones fundamentales: lo que Carpentier entiende, o parece entender, por: 1) lenguaje; 2) literatura; 3) realidad. Habrá que asumir el riesgo y denominar estas tres posiciones, que yo llamaría: 1) cratilismo; 2) ionismo; 3) platonismo.

Dice Carpentier:

Hoy conocemos los nombres de las cosas, las formas de las cosas, la textura de las cosas nuestras; sabemos dónde están nuestros enemigos internos y externos; nos hemos forjado un lenguaje apto para expresar nuestras realidades, y el acontecimiento que nos venga al encuentro hallará en nosotros, novelistas de América Latina, los testigos, cronistas e intérpretes de nuestra gran realidad latinoamericana. (Carpentier, 1975:135)

La cita concentra, de algún modo, las tres posiciones, lingüística, estética y ontológica. Las cosas, la cosa americana, la realidad americana, posee un nombre propio: si lo real maravilloso comienza con el descubrimiento de América, con en el Diario de Colón y la Verdadera Historia de Bernal Díaz del Castillo, la ineptitud del español peninsular para expresar el Nuevo Mundo acreditaría, entonces, un cratilismo del lenguaje. La cosas, entonces, la cosa-América, tiene un nombre, anterior al encuentro de culturas. La tarea (o, para usar una palabra más cara a Carpentier, "la misión") del novelista latinoamericano es expresar, 
traducir, hacer inteligible, esa esencia que es anterior y que se manifiesta en la palabra precisa, encontrada: como en el lon platónico, el poeta es el intérprete de un mensaje que no viene de él, del mismo modo que Carpentier encuentra la estética de su novela no en la experimentación narrativa, sino viajando por Haití y el Orinoco: se podría decir, con una terminología más moderna, el referente América Latina, anterior a cualquier lenguaje, a priori barroco y real-maravilloso, es el postulado del que se parte para la concepción de la novela americana.

En términos de estética, esta nociones a veces se confunden en un archipiélago de ideas que son más bien lugares comunes como el vitalismo, el expresionismo, la idea de representatividad de un escritor respecto de su pueblo, el nacionalismo o el regionalismo: nebulosa de nociones que a veces hacen pensar en el romanticismo. Dicho sea de paso: el romanticismo, como el barroco, también se alza contra el clasicismo y también es en cierto modo un padre putativo del surrealismo, lo cual lo convertiría casi en abuelo de eso que se llama real maravilloso. O quizás no hay ahí ninguna estética americana, sino la reiteración de esquemas ya naturalizados por el pensamiento europeo, pensamiento en el que el mismo Carpentier se formó, trayendo, de su temporada surrealista en Francia, la necesidad de forjar la nueva novela de América Latina. Y, quizás, creyendo encontrar naturalmente, como el aura del paisaje benjaminiana, lo propio de la nueva novela en la selva virgen de América Latina, no hacía otra cosa que acceder a una visión ya esquematizada por pensamientos foráneos. Lo propio de América había sido inventado por los europeos: lo real maravilloso, como lo sospecha Saer, es un invento de Europa, no de América.

\section{5.}

Johan Moritz Rugendas fue un paisajista europeo que, acicateado por el naturalismo de Von Humboldt, viajó a América a pintar las exuberancias de esas tierras, buscando, mediante la plástica, la esencia de las cosas. Este arte es decididamente rentable, ya que el exotismo de la selva amazónica o los barroquismos de los paisajes centroamericanos permiten que Rugendas pueda vender fácilmente sus cuadros en Europa, mercado ávido de productos 
característicos del trópico, sean frutos exóticos o paisajes naturales. Ahora bien, el anhelo secreto de Rugendas era conocer la pampa: Von Humboldt no quería que perdiera tiempo con tan insignificante paisaje y con tan largo e inútil viaje. Sin embargo el artista, que sabía que a pesar de su talento tenía algo de comerciante y otro poco artesano, presentía que en el vacío dilatado de la llanura podía encontrar el reverso de su trabajo, el otro lado de su arte.

No sería, quizás, un abuso leer en Un episodio en la vida del pintor viajero, de César Aira, el mismo carpetazo que nos da El entenado respecto de la estética latinoamericanista. La novela de Aira es muy interesante porque pone en juego en la trama de la historia lo que en Saer aparece más bien en términos de imagen. Esto es: oponer a la exuberancia paisajística de la selva y del trópico, a ese referente, a esa realidad previa de la que parte la estética de Carpentier, el imaginario de una llanura dilatada, límpida, vaciada, que trágicamente el pintor airiano no alcanza a conocer.

De esta imagen se sirve Saer tanto en sus novelas como en sus ensayos. En estos últimos, la metáfora de la selva ha sido a menudo mal interpretada. "La selva espesa de lo real" no es la complejidad del mundo o del universo, exuberancia cósmica o, quizás, ontológica, en la que el escritor se sumerge para narrar. La selva espesa de lo real es justamente el espejismo de una realidad dada y categorizada previamente, y que, como el pintor airiano, el narrador debe atravesar, a fuerza de machete, para dar con lo material: aquello que, desprovisto de signo, pueda entrar, como materia, en el trabajo de la narración.

Aunque la imagen de la lisura pampeana o de la llanura no aparece como contraparte en sus ensayos enfrentada a la realidad selvática, sí el lector puede encontrar una cierta modulación de la misma en el despojamiento significante del paisaje saeriano, en la lisura de la Zona, sea del río sin orillas, del mar mezclado con el cielo o de la pampa misma. Río inabarcable, cielo-mar, pampa: todo cae bajo el común denominador de llanura. $Y$ este paisaje, esta geografía, es, en la narración saeriana, mudo, espeso, insignificante. También el narrador del El entenado se adentra en la selva de lo real hasta llegar a las costas lisas de lo material. La intemperie metafórica y literal de la que debe partir, para Saer, todo narrador, y quizás también todo artista. 


\section{Bibliografía}

Aira, C. (1987): "Zona peligrosa”, en El porteño. Buenos Aires.

(2000): Un episodio en la vida del pintor viajero. Beatriz Viterbo, Rosario, 2003.

Carpentier, A. (1975), "El barroco y lo real maravilloso", en La literatura latinoamericana en vísperas del nuevo siglo y otros ensayos, conferencia dictada en el Ateneo de Caracas. Siglo XXI, México, 1982.

Dalmaroni, M. y Merbilháa, M. (2000): “Un azar convertido en don'. Juan José Saer y el relato de la percepción", en Historia crítica de la literatura argentina, Noé Jitrik, Tomo 11 (dirigido por Elsa Drucaroff) "La narración gana la partida”. Emecé, Buenos Aires, 321-343.

Dalmaroni, M.: "El largo camino del 'silencio' al 'consenso'. La recepción de Saer en la Argentina", en El entenado Saer, J. J., -Glosa, Paris, Col. Archivos- ALLCA XX, edición crítica a cargo de Julio Premat, 607-664, (en prensa).

Gramuglio, M. T. (1986): “El lugar de Saer”, en Juan José Saer por Juan José Saer. Celtia, Buenos Aires.

Llanera, A. (1997): Realismo mágico y lo real maravilloso, una cuestión de verosimilitud. Hyspamérica, Madrid.

Premat, J. (2002): La dicha de Saturno. Beatriz Viterbo, Rosario.

Saer, J. J. (1964): Responso. Seix Barral, Buenos Aires, 2004.

(1969): Cicatrices. Seix Barral, Buenos Aires, 2005.

(1974): El limonero real. Seix Barral, Buenos Aires, 2006.

(1980): Nadie nada nunca. Seix Barral, Buenos Aires, 2004.

(1983): El entenado. Seix Barral, Buenos Aires, 2005.

(1987): "Soy argentino, no latinoamericano", entrevista con Leonardo Moledo, "Cultura y Nación". Clarín, Buenos Aires.

(1990): Diálogo Piglia-Saer. Por un relato futuro. UNL, Santa Fe.

(1994): La pesquisa. Seix Barral, Buenos Aires, 2002.

(1997): El concepto de ficción. Ariel, Buenos Aires.

(2001): Cuentos completos (1957-2000). Seix Barral, Buenos Aires.

Stern, M. (1984): "Juan José Saer: construcción y teoría de la ficción narrativa", en Hispamérica, Año XIII, N³7, 15-30. 